International Journal on Applied Bioengineering, Vol.3, No.1, January 2009

\title{
AQUACULTURE INFORMATICS: INTEGRATION OF INFORMATION TECHNOLOGY AND AQUACULTURE IN INDIA
}

\author{
Inbakandan. D1, Radhika Rajasree ${ }^{2}$, Stanley Abraham. $\mathrm{L}^{3}$, Ganesh Kumar. $\mathrm{V}^{4}$, Manoharan. $\mathbf{N}^{5}$, Venkatesan. $\mathbf{R}^{6}$ and Ajmal Khan. $\mathbf{S}^{7}$ \\ ${ }^{1,2,3,4,5}$ Centre for Ocean Research, Sathyabama University, Chennai, India \\ ${ }^{6}$ National Institute of Ocean Technology, Chennai, ${ }^{7}$ Centre for Advance studies in Marine biology, Annamalai University, Port Nova
}

\begin{abstract}
Aquaculture is now viewed as a strong option to increase fish production as it plays a vital role in providing food security in India. Aquaculture informatics can be described as the scientific application of Information technology in biological concepts that enhance the productivity and economic viability of aquaculture sectors. Though there are lot of developments in various aquaculture sectors around the world, Aquaculture in India is still in infancy to use the information from different parts of the country. Advances in electronic communication, combined with specific cooperative efforts, should be used to increase the information exchange in the region. It is nation's part to educate the fish farmers through community based organization and to provide an information system, in low cost, to fulfill their requirements. In order to develop a single hub for the integrated activity, some community based organizations are formed like fish farmers association, self help group or aqua club. This paper is on the integration of aquaculture information based tools under one hub to design to work through a community based system.
\end{abstract}

KEYWORDS: Aquaculture, Informatics, Precision farming, Community based organization, Farmer Information System, Shrimp, Crop

\section{INTRODUCTION}

Aquaculture would face many challenges over the next decade, notably, combating diseases and epizootics, brood stock improvement and domestication, development of appropriate feeds and feeding mechanisms, hatchery and grow-out technology, as well as water quality management. All these are the present considerable scopes for biotechnological and other technology interventions. [1] Aquaculture informatics or Aquainformatics can be described as the scientific application of information technology in biological concepts that enhance the productivity and economic viability of its various industrial sectors.

The amount of digitally available Aquaculture information is growing exponentially and appropriate steps need to be undertaken to facilitate sharing and consequently reduce costs. These Aquaculture information resources, sometimes located in proprietary applications and using dissimilar data models, hamper information sharing [2]. Additionally, information system designers are sometimes unaware of existing design methodologies, data description standards or freely available tools or applications. The goal of this paper is to bring these new implementers together in a single hub, thus providing both for existing systems and allowing them to contribute to the creation of new ones.

\section{AQUACULTURE IN INDIA}

India ranks fourth in global fish production [3] and only second [4] to China in the inland fish production. Around seven million people of India are engaged in fisheries and ancillary industries. The fisheries sector contributes around 1.5 percent of the total GDP and around 5 percent to the GDP from the agriculture sector. The fisheries sector contributes over Rupees 6,000 crores to the export earnings. The potential brackish water area available in the coastal region of the country for shrimp culture is estimated between 1.2 and 1.4 million ha. Presently an area of about $1,57,000$ ha is under culture with an average production of about $1,00,000$ tones per year. Cultured shrimps contribute about 50 percent of the total shrimp exports. Presently the technology adopted ranges from traditional to improved traditional culture within the Coastal Regulation Zone (CRZ) and extensive shrimp farming aside the CRZ. About 91 percent of the shrimp growers have a holding between $0-2$ ha, 6 percent between 2 and 5 ha and the remaining 3 percent have an area of 5 ha and above. There are around 260 shrimp hatcheries in this country with an installed production capacity of 11 billion times. About 200 hatcheries are in operation producing about 7 billion shrimp larvae. There are about 33 feed mills whose annual production capacity is $1,50,000 \mathrm{mt}$. The current feed requirement is in the tune of $1,35,000 \mathrm{mt}$. Shrimp farming provides direct employment to about 0.3 million people and its ancillary units provide employment to 0.6-0.7 million people. Environmental issue has always been the point of conflict in shrimp farming development (Supreme Court's Judgment in Writ Petition No 561 (C) of 1994). While production from capture fisheries has stagnated, aquaculture is now viewed as a strong option to increase fish production as it plays a vital role in providing food security [5].

India has moved from the food shortages to selfsufficiency and even exports [6]. While productions of aquaculture commodities have increased tremendously in the last few years, there has been a drastic reduction in productivity and quality. Inefficient resource utilization and unsustainable fishing and aquaculture practice like use of saline water in agriculture land and intensive culture resulted in imbalance in the Industry. Another major 
difficulty is competing nations. In order to gain an advantage in the highly competitive global market and to make major profits in the export market, there is an increasing demand for professionally qualified people in this sector. In this context, Aquaculture informatics promises rays of hope. It has a lot of potential in vitalizing the industry and generating huge job opportunities in this sector.

\section{ROLE OF INFORMATION TECHNOLOGY}

The role of information technology becomes more and more influential to ways of life for all people including fish farmers due to its rapid development. Information technology now represents one of the suiTable- tools for the prosperity of Indian aquaculture. In broad sense, Aquaculture informatics is the application of Information Technology in the field of aquaculture. The application may be in the form of precision farming, analyzing aquaculture information, developing database and algorithms for aquaculture research, analyzing genetic information, transfer of technology, Aqua-business etc. Various Aquaculture informatics based tools like Decision support systems, Remote sensing, Farmer Information System, Management Information System, Geographical Information System, Farm management software and aquaculture databases can provide effective and timely solutions to many problems in aquaculture $[7,8]$. ( see Fig 1)

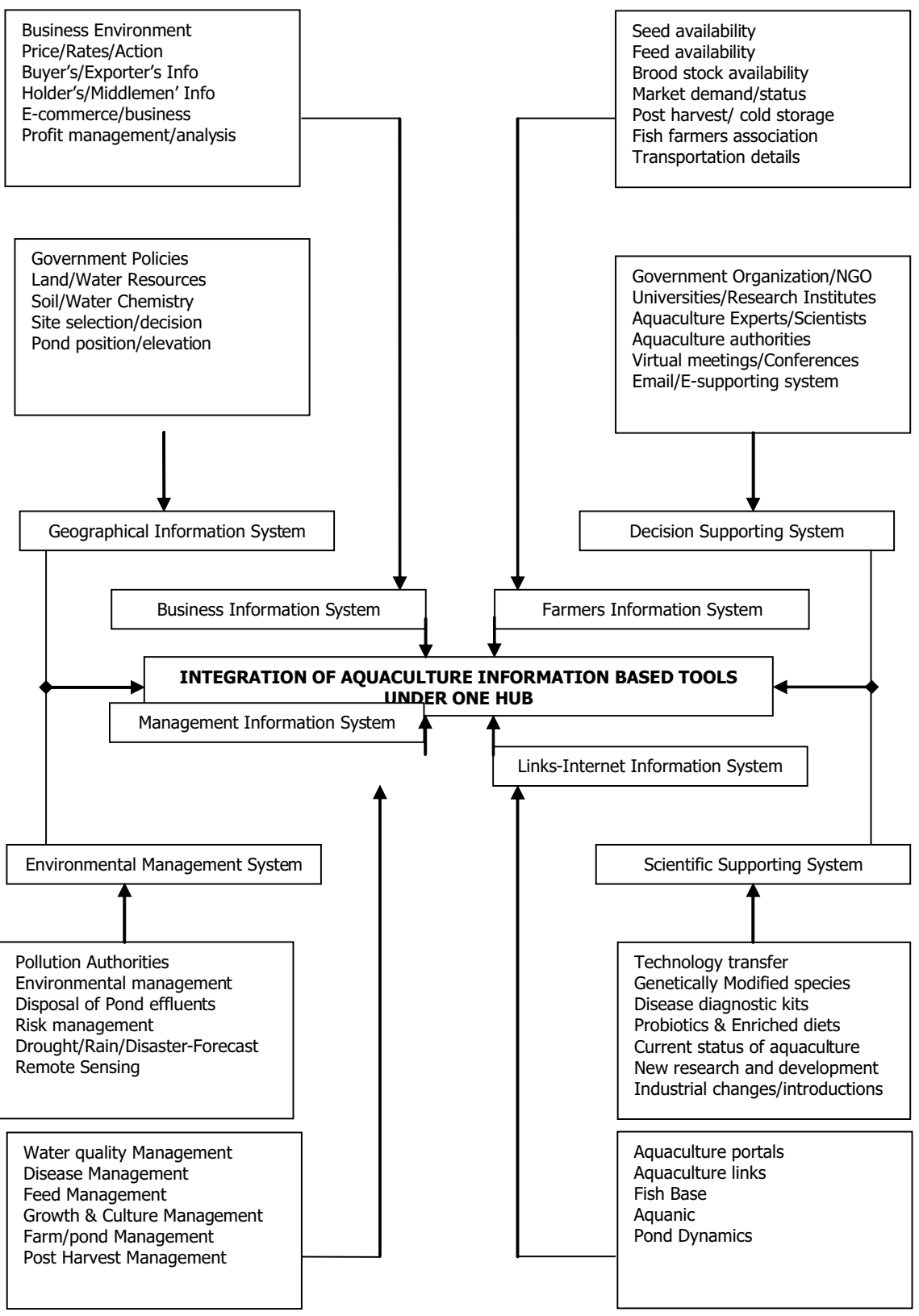

Fig. 1. A flow chart representation of Aquaculture Informatics 
Inbakandan D. et al: Aquaculture Informatics : Integration of Information...

To develop the aquaculture sector improved communication strategies are needed, particularly through extension delivery system and Information Technology [9]. Information is power for any sector. Especially in farming, information is the

most important resource that our farming systems are impoverished of [10]. The fish farmers are indigent of the information about potential demand for their fish crops in a specified time schedule, process prevailing in different places, availability of aquaculture inputs such as seed, feed and weather conditions etc. Consequently, fish farmers have not been able to tune themselves to cover their farm area with appropriate fish crops that might minimize risks and maximize profits. Aquaculture informatics is the key to triumph over these hurdles by using its various technologies. For instance, Farmers Information system is a unique type of system where a farmer can get all the aquaculture related information regarding various fish crops, aqua feed details, market information, credit details, transport details and more, at single platform so that he can plan each and every stage of his fish husbandry and can earn maximum.

\section{DECISION-MAKING}

Decision making at critical stages is important for the successful fish production, for that the modern farmer often relies on aquaculture specialists to assist him. Unfortunately, aquaculture specialists are not available for consultation at a point of time when fish farmers need them. To solve this problem, Expert system will be developed. Expert system will be a special computer program designed to capture the knowledge generated by the vast network of Aquaculture scientists and encapsulate their expertise to help fish farmers and extension workers in making the required decision for raising the successful fish. The expert system will be designed to answer questions entered to a computer on such diversified topics even for individual fish crops [11]. For example "Shrimp Marketing Advisor" is an expert system for determining marketing alternatives and supports shrimp producers in finding optimal strategies. Individual shrimp farm conditions are considered. Information on post harvest and cold storage availability, price level, price trends government program eligibility, and timing are required as input data. The application of genetics principles to increase production from aquatic animals currently lags far behind that of the plant and livestock sectors. Only a small percentage of farmed aquatic species have been subject to genetic improvement programs [12].

\section{INTEGRATING TECHNOLOGIES}

Ecological zoning system, methodology and software use several databases, models and decision support tools for better planning, management and monitoring of land resources. Expert system is motivating researchers and professionals to investigate possible application of Expert System in diverse disciplines or modern aquaculture. The use of simulation models as decision support systems can offer an ideal means of achieving economical, environmentally safe and sustainable fish management. "Precision farming" is a current buzzword coined among aquaculture and agriculture circles [13]. The term precision farming means carefully tailoring soil and water management to fit the different conditions found in each pond or farm. Precision farming is sometimes called "prescription farming", "site specific farming" or "variable rate technology". Precision farming is the site-specific management practices are adopted giving due consideration to the spatial variability of land in order to maximize fish production and minimize the environmental damage. It has caused a focus on the use of three technologies that are Remote sensing, Geographic Information System (GIS) and Global Positioning Systems (GPS) [14]. Precision Farming has beenevolved to prevent the excess and under-application of inputs and to avoid their ill effects. Soil fertility and water availability status differs from place to place even in the same field. The population of weed is never uniform throughout the fish farm and the pest and predator population also shows variability. Even a pathogen attack would not be uniform throughout the field. Precision aquaculture emphasizes on this aspect and deals with judicious fish management at micro level wherein only required amount of inputs are applied. Fish farmers have services available that involves satellites connecting data, transmitting location information, or providing data from a variety of sources. Fish farmers can analyze this satellite information or they can rely on companies to do this service for them for a fee. Precision farming will make a strong impact on the way fish farmers manage their farm operations in the future. Precision farming envisages precise packages of fish cultivation at micro level, which enable it to increase the productivity. Precision farming techniques closely meet environmental guidelines because fertilizers and pond preparation can be managed to apply to minimum needed for effectiveness.

Remote sensing technology by virtue of many advantages has become a very useful tool in the hand of scientists, planners and administrators to obtain accurate information on various aspects of fish crops, soil, water and land use. GIS technology is being increasingly employed by different users to create resource databases and to arrive at appropriate solutions/strategies for sustainable development of aquaculture resources [15]. The application of remote sensing and GIS techniques in the management of aquaculture resources are increasing 
rapidly due to improvement in space borne remote sensing satellites in terms of spatial, special, temporal and radiometric resolutions. Many of conventional approaches of handling multi-thematic information to arrive at optimal solutions are being computerized using GIS utilities. GPS makes use of a series of satellites that identify the location of farm equipment within a meter of an actual site in the field [16].

\section{GENETIC IMPROVEMENT OF FARMED TILAPIA}

The Genetic Improvement of Farmed Tilapia (GIFT) project in Asia is an example of a programmed aimed at examining the genetics of an important farmed fish species [17]. The GIFT project has been working with Nile tilapia hybrids and strains in culture around the region, with a view to development of purebred lines and the distribution of strains of improved performance to farmers. The programme is a collaborative effort between ICLARM (International Centre for Living Aquatic Resources Management) headquartered in Malaysia and research institutions in Malaysia, Philippines, UK and USA. The programme has not yet reached the full commercial phase and the 'improved' tilapia in most of the participating countries is still under evaluation by fisheries scientists. The program has, however, shown considerable potential for improving farm production. Similar breeding programmes for commercially important carps could bring comparable benefits. Indeed, because carp fry production is typically more centralized that is the case for tilapia, the spread of improved stocks could occur more readily. The question is whether Indian fish farmers are aware of this technology transfer or not $[18,19,20]$.

\section{TRANSGENIC TECHNOLOGIES}

Transgenic technologies can enhance growth rates and market size, feed conversion ratios, resistance to diseases, sterility issues and tolerance of extreme environmental conditions. In the shrimp aquaculture sector, transgenic shrimp have been reported, but there has been no successful development till date for commercial culture. However, the use of transgenic organisms in aquaculture (as in other sectors) is controversial and issues of consumer education and acceptance must be addressed [21]. Carp and tilapia culture in Asia is benefiting from genetics research in a number of areas, including genetic sequencing and the development of specific genetic markers. Markers are short unique pieces of genetic code that can help locate genes that are important for growth, sex determination factors or disease susceptibility. Improving genetic understanding across millions of small-scale farms in India is a difficult challenge, especially since traditional approaches have focused on improvement of core stocks that can then be distributed to farmers. [22, 23]

\section{NUCLEIC ACID (DNA \& RNA) BASED PROBES}

Considering the major contribution of Penaeus monodon to the global shrimp production and the economic loses encountered due to both facultative and opportunistic disease outbreaks [24]. It is appropriate and timely to concentrate further research to develop specific and nonspecific resistant broodstock - especially for P. monodon. Infectious disease is currently the single most devastating problem in shrimp culture and presents ongoing threats to other aquaculture sectors. In addition, there is increasing concern over the consequences of newly emerging disease in aquaculture. Conventional methods of controlling such diseases, such as chemotherapeutants, are ineffective for many new pathogens; thus, molecular techniques are receiving increasing attention for pathogen screening and identification. The increased sensitivity and specificity conferred by nucleic acid (DNA \& RNA) based probes has provided significant inroads for early detection of diseases and identification of sub-clinical carriers of infections. This has had a direct effect on enhancing preventive management and control of disease in cultured species. In shrimp aquaculture, commercially available molecular probes have been developed for type-A baculo virus, whereas commercial probes for other viral pathogens, such as white spot are still under development. As noted above, nucleic acid probes are extremely sensitive and can detect microbial infections before they progress to produce clinical signs. But this information should be encapsulated to fish farmers, which in turn pinpoint the need of information and communication technology or Integration of aquaculture information based tools under one hub [25].

\section{E-PROCUREMENT AND E-AUCTION}

The values of men, material and money are saved if we introduce the e-procurement and e-auction. If fish farmers in India are aware of e-commerce then they can connect to the business environment from their place with the help of Internet through e-procurement and e-auction. For example, Biz Dimension Co., Ltd. is the leading service provider of e-procurement and e-auction in Thailand. They have been helping hundreds of organizations, both in the private and public sectors, in streamlining and consolidating their procurement activities on numerous products (including shrimps and fin fishes) and services. They have achieved a success rate of over $95 \%$ on all auctions and their clients' total accumulated cost savings have exceeded Baht 100 million (www.bizdimension.com). We can achieve these kinds of e business activities through the Integration of aquaculture information based tools under one hub. 
Inbakandan D. et al: Aquaculture Informatics : Integration of Information...

\section{$X$. SHORT MESSAGE SERVICE}

As mobile phones are common to each level of community, information can be passed thorough short message service also. As an example, ThaiFarmZone.com is launching a new information service for entrepreneurs and interested parties in the Thai shrimp industry. The new service is to deliver the daily black tiger shrimp prices from Mahachai central market at Samutsakorn province to the subscriber's mobile phone through short message service (SMS). The SMS shrimp price service is the latest feature provided by the website to serve the Thai agricultural and food sectors with an aim to make useful information accessible by users from anywhere at any time. This can be done by Integration of aquaculture information based tools under one hub.

\section{NEED FOR INFORMATION CENTERS}

The advances made by information technology and its impact on aquaculture calls for a renewed thinking with regards to farming production, research and extension systems. A number of aquaculture revolutions over the past two decades have made the industry in India subsistent and sustainable but not self-sufficient. The plateau in the production levels and the difference between data acquired through research and ground truth with the farmers indicate that the information systems require fine tuning to decrease the gap between production and research findings. The backbone for all future information system endeavors will be to transform the aquaculture from subsistence level to commercial operations.

Various aquaculture and rural development projects support and initiate formation of different types of beneficiary organizations and provide technical and financial assistance to them. Such group approach to reorganize extension services has become the rule of the day. However organizations formed by farmers self initiative and engaged directly in providing extension services is rare.

\section{INTEGRATION OF AQUACULTURE INFORMATION BASED TOOLS UNDER ONE HUB}

The information system designers, managers and owners will be have access not only to a website that brings together different resource types, but also to mechanisms that facilitate information sharing, consensus building and awareness raising. The aim is to provide all the tools necessary to facilitate interoperability between existing datasets and the creation of new systems using consistent and commonly accepted standards.

Efforts in the development of methodologies, standards and application development in the areas of Aquaculture and Rural Development are at present widely dispersed. The goal of this paper is to create a Hub for Aquaculture Information Management Systems, to allow sharing and promoting the uptake of common methodologies, standards and applications. The expected benefits are reduction in the costs for creation of new systems and increase in the quality of services provided to the users [26].

Due to globalization and liberalization, there is a change in the public extension approach where associations and self help groups are involved in educating the farming community. Integration of aquaculture information based tools in a single hub will be a design to work through a group of community or an association. Success of providing farm information depends on the public participation in these associations. This approach will create a confidence among fish farmers in team work and group mobilization. Fish farmers can learn, online, the best farm practices for their fish, prevailing prices and price trends of fishes in the Indian and world markets. In addition intricacies of risk management and the meteorological data could be accessed. Thus individual farmer get the benefit of expert knowledge for the cultivation and management of their fish crops.

\section{COMMUNITY BASED ORGANIZATION}

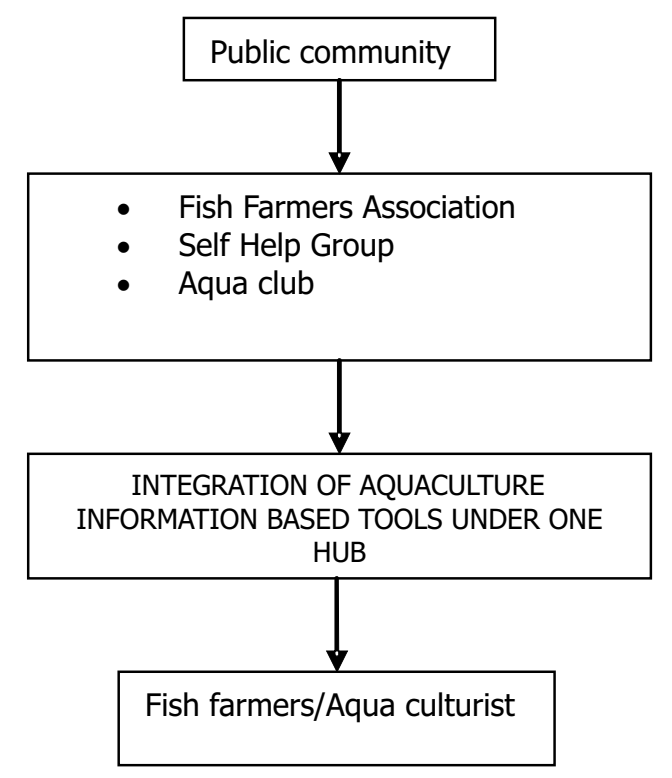

Fig. 2. Structure of the community based organization

Integration of Information technology with aquaculture in India is a societal task, which makes an attractive unit for the technical support to aqua farmers [27]. Providing information or introducing computer based skills to farmers is a task which can be taken up through a community based organization by fish farmers association / self help group / aqua club / bio village. 


\section{Example 1}

In the state of Tamil Nadu, on the east coast of India shrimp farmers in the Thanjavur district have formed village level associations and organize regular meetings to follow good management practices for achieving eco-friendly and sustainable shrimp farming. One of the best examples of this association is the ÇThambikottai-kdakadu Shrimp Farmers AssociationÇ. The members of this Association consult themselves before initiating pond preparation, introducing water in their ponds, selection and stocking of seed, feed management, shrimp health management, prevention of disease, formation of separate channels for draining out waste water, harvesting time, fixing of price, etc.

The Association members also inspect the shrimp hatcheries located at Chennai and Marakanam areas and collect seed samples for testing in three different PCR laboratories to ascertain the presence/ absence of pathogens. The tested seed is purchased in bulk, which is then divided amongst the members of the association to suit their requirement. If a viral disease affects any of the farmer's crop, all precautionary measures are taken to prevent the spread of the disease to the other ponds. The association also compensates the affected farmer's loss. The association takes responsibility of civil infrastructure like laying roads and providing drainage canal and street lamps to the villages adjacent to shrimp farm cluster. The association also organizes meeting of the members on fortnightly basis, discusses and solves their problems with mutual consent.

\section{Example 2}

To promote cooperative approach in management of shrimp farming activities and other common issues that commonly arise in cluster-based shrimp farms, aqua clubs have been set up in Andhra Pradesh. A total of 128 aqua clubs with a membership of 3367 farmers is now existing in the Stat However, one of the best initiatives of this kind is the Sri Subrahmanyeshwara (SS) aqua club in Mogalthur village in West Godavari district of Andhra Pradesh. The SS aqua club comprised of 58 farmers with 108 shrimp ponds spread over the area of 58 ha is mostly involved in smallscale, practice and improved traditional farming method with low cost investments. Based on the technical inputs provided by the Network of Aquaculture Centers in Asia Pacific (NACA), Bangkok and the Marine Products Export Development Authority, Kochi, the farm level 'better management practices or the BMPs were demonstrated in the shrimp ponds of the SS aqua club with great success.

The above two initiatives by the shrimp farmers in the states of Tamil Nadu and Andhra Pradesh need to be replicated in other coastal states where shrimp farming is fast developing on commercial-scales.

\section{ROLE OF SELF-HELP GROUPS IN FISHERIES (SHGS)}

The southern districts of Tamil Nadu have witnessed significant increase in the number of fisherwomen Self Help Groups (SHGs). Punnakkayal village in Tamil Nadu has the largest number of SHGs in an Indian village with over 50 groups consisting exclusively of fisherwomen.

Presently, there are several examples of successful fisherwomen SHGs in the region and their experiences need to be promoted to other states. Examples: The fish market at Neelankarai, a coastal village of Chennai on the east coast of India, is managed by fisherwomen belonging to 12 SHGs. The management practices established by this group demonstrate their efficiency and unity. Similarly, the SHGs formed by fisherwomen in Vellapatty village in Tuticorin has enabled its member to conduct individual business proposals involving a wide range of activities, including fattening of crabs for sale in the local market. These SHGs also have good linkages with the NGOs who have helped them in promotion of their business.

\section{CONCLUSION}

Though there are significant developments in various aquaculture sectors around the world, aquaculture in India is still at its infancy and to use the information from different parts of the country. It is nation's part to educate fish farmers and to provide an information system through farmers association [29], in low cost, to fulfill their requirements. Industries and Research institutes in India will work on it for the blue revolution. Activities that improve communication and networking within the region were highlighted as an important means of developing and communicating the knowledge base of aquaculture. Advances in electronic communication, combined with specific cooperative efforts, should be used to increase the information exchange in the region ${ }^{14}$. For efficient management of aquaculture resources, the information generated by various institutes or organizations should be brought under one hub for the benefit of research scientists as well as fish farmers. The information communication technology such as the Internet is now dynamically changing our life style and social consciousness will provide us a best tool for the information sharing in the field of Aquaculture. Several models such as fish growth prediction, decision support, precision farming and GIS ensure effective and sustainable fish production. A large number of trained professionals in aquaculture along with Information Technology are the immediate need of this Aquaculture informatics industry in order to accelerate the research, production and implementation. Thus, the 
Inbakandan D. et al: Aquaculture Informatics : Integration of Information...

importance of the studies on Aquaculture informatics is undoubtedly increasing and career / business opportunities are booming. The success of the Blue Revolution of the earlier decades will now have to be repeated through a "Digital Revolution" for an evergreen revolution.

\section{REFERENCES}

[1] Pillay, The role of aquaculture in fishery development and management, journal fisheries research board of Canada, Vol 30, p 2202-2217, 1973.

[2] Kaloyanova, Information technologies and standards for agricultural information resources management, IAALD Quarterly Bulletin, LII, 1/2, 2007

[3] Sarada, Ravisankar, Krishnan Anandanarayanan, Instabilities in Indian seafood exports: sources, shortfalls and stabilization measures, a time series analysis, PROJECT NO. CIBA/SSD/03, CASE STUDY NO. CIBA/SSD/JUNE 2005, 31P.

[4] Ayyapan, THE ECONOMIC TIMES, 2 Nov, 2007.

[5] Ayyappan. \& Diwan, 2004. Road map to increase fish production and productivity in India. Fishing chimes, 24(4): p24-26.

[6] FAO report, 2001. The state of world fisheries and aquaculture 2000. Food and agriculture organization of United Nations. Rome

[7] Powell, Information to the people: cooperation between the library and agricultural extension. Journal of agricultural and food information, 2 (2) 1994: 19-24.

[8] Arunraju \& Bhatnagar, 2004. Future thrust of agriculture-agroinformatics. Bioinformatics India, 2:93-97.

[9] Haylor \& Bland, 2001. Integrating aquaculture into rural development in coastal and inland areas, technical proceedings of the conference on aquaculture in the third millennium, Bangkok, Thailand, 20-25 February 2000. Pp.73.81. Naca, Bangkok and FAO, ROME.

[10] Aina, Information for successful agriculture. Third world libraries, 2 (1) 1991: 55-58.

[11] Phillips, Boyd, \& Edwards, 2001. Systems approach to aquaculture management., and Subasinghe, Bueno, M.J. Phillips, Hough, Mcgladdery \& J.R. Arthur, eds. Aquaculture in the third millennium. Technical proceedings of the conference on aquaculture in the third millennium, Bangkok, Thailand, 20-25 February 2000. Pp. 239-247. Naca, Bangkok and fFAO Rome.
[12] Raman Nair, R. Agricultural and farm information system for Kerala. Proceedings of the ila national seminar, December 1996. Directorate of public libraries, Andhra Pradesh, Vijayawada, laslic, 1996: 298-312.

[13] Mandal and Ghosh, Precision farming - the emerging concept of agriculture for today and tomorrow, current science, vol. 79, no. 12, 25 December 2000.

[14] Chuon, 1999. Application of resource information technologies (GIS/GPS/RS) in forest land \& resources management, sustainable management of resources in the lower Mekong Basin Workshop Proceedings: October 18 -20, 1999 Hanoi, Vietnam.

[15] Meaden, g.j.; Do Chi, 1996. T. Geographical information systems: applications to machine fisheries. Fao fisheries technical paper. No. 356. Rome, FAO. 1996.335p.

[16] Salam m.a. Et al., 2003 a comparisons of development opportunities for crab and shrimp aquaculture in southwestern Bangladesh, using GIS modeling. Aquaculture 220 (2003) 477-494.

[17] Gupta m. V. \& acosta b. O. 2004. From drawing board to dinning Table-: the success story of the gift project. Naga 27:4-14.

[18] M.v. Gupta and B.O. Acosta (eds.) Fish genetics research in member countries and institutions of the international network on genetics in aquaculture. ICLARM conf. Proc. 64, 179p.

[19] Basavaraju, y., Penman, D.J. and Mair, G.C. 2002. Genetic status and strategies for improvement of common carp (cyprinus carpio) in karnataka, India evaluation of stocks for the development of a breeding programme. Pp. 29-36.

[20] Penman, Hussain, Mcandrew, Mazid, Proceedings of a workshop on ge netic management and improvement strategies for exotic carps in Bangladesh, 12-14 February 2002, Dhaka, Bangladesh. Bangladesh fisheries research institute, Mymensingh, Bangladesh. 123p.

[21] Benzie, J.A.H. 1998. Penaeid genetics and biotechnology. Aquaculture, 164:23-47.

[22] Penman, D.J. 2001. Overview of aquaculture genetics research in the institute of aquaculture, university of stirling, p. 145-149.

[23] Gupta and Acosta (eds.) Fish genetics research in member countries and institutions of the international network on genetics in aquaculture. Iclarm conf. Proc. 64, $179 p$. 
[24] Durand, Lightner, Nunan, Redman, Mari, Bonami, 1996. Application of gene probes as diagnostic tools for white spot baculovirus (wsbv) of penaeid shrimp. Dis. Aqua. Org. 27, 59-66.

[25] Ayyappan,. Ponniah, Reddy, Jana and Mahapatra and Basavaraju 2001. Aquaculture genetics research in India: an overview, p. 43-50.

[26] Mangla, Agricultural libraries in India: an overall view. Journal of library and information science (India) 13 (2) dec 1988: 97-98.

[27] Shaw, Ralph and Krishna, Report on library and bibliographical services for agricultural teaching and research in India. New Delhi, ICAR, 1957.

[28] Ayyappan, 2003. Farmer associations - experiences in poverty alleviation from eastern India, a presentation to the sub-committee on aquaculture of the committee on fisheries of the food and agriculture organization of the UN, august 2003, Trondhiem, Norway.

[29] Kongkeo, 2001. Current status and development trends of aquaculture in the Asian region. In r.p. Subasinghe, p. Bueno, m.j. Phillips, c. Hough, s.e. Mcgladdery \& j.r. Arthur, eds. Aquaculture in the third millennium. Technical proceedings of the conference on aquaculture in the third millennium, Bangkok, Thailand, 20-25 February 2000. Pp. 267-293. NACA, Bangkok and FAO, Rome.
[30] Yoganandhan. et al. Screening the organs for early detection of white spot syndrome virus in penaeus indicus by histopathology and PCR techniques. Aquaculture 215(2003) 21-29.

[31] Ernst et al., 2000. Aqua farm: simulation and decision support for aquaculture facility design and management planning. Aqua cultural engineering 23 (2000) 121-179

[32] Salam, et al., 2003. A comparison of development opportunities for crab and shrimp aquaculture in southwestern Bangladesh, using GIS modeling. Aquaculture 220:477-494.

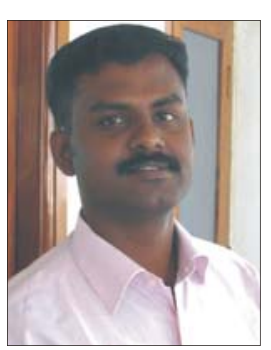

Mr.Inbakandan.D is a Scientist $C$ in Sathyabama University, Centre for Ocean Research. He has completed M.Sc., Aquaculture, in University of Madras and Advance Diploma in applied Bioinformatics, Bll, Delhi. Doing Ph. D at CAS in Marine Biology, Annmalai University (Studies on Marine biofilms and its control by silver nanoparticles biosynthesized by Marine sponges. He has ten years of experience in the field of Marine Biology, Aquaculture, Biofouling and Biotechnological Research \& Development and as of. Published papers in 4 International journals, 2 National journals and 10 Symposiums/Conferences. 